\title{
An empirical study of graduate student mobility underpinning research universities
}

\author{
Takao Furukawa $\cdot$ Nobuyuki Shirakawa $\cdot$ Kumi Okuwada
}

Published online: 6 November 2012

(C) The Author(s) 2012. This article is published with open access at Springerlink.com

\begin{abstract}
The issue of international student mobility has had a profound effect on policy decision-making in the higher education system of essentially every country; however, the statistical data on this subject are insufficient, especially for graduate students. The purposes of this study are to substantiate the state of international mobility among talented graduate students in the sciences and engineering who will publish scholarly research in their future career and to present the mechanism of their moves between institutions. This paper quantitatively analyzes the trajectories of more than 7,000 scientists and engineers beginning at graduate school, obtained from the biographical notes attached to journal articles for authors in the fields of computer vision, robotics, and electron devices. The results suggest that mobility in various engineering fields at world-class research universities is subject to varied pull and push factors. In the fields of computer vision and robotics, a high world university ranking is a significant pull factor in the global mobility of graduate students, which may promote a US-dominated stratification between institutions of higher education, since the institutions at the top end of these rankings are generally in the United States. In contrast, in the field of electron devices, employment for highly skilled workers in domestic industries seems to act as an alternative pull factor for talented graduate students. This article also sheds light on the status of the universities that underpin first-tier research universities by providing undergraduate students to them, an important role that tends to be concealed in the world university rankings. Furthermore, this article suggests the existence of complementary relationships between the globally top-ranked research universities and the exporting top national research universities in various countries, a relationship that is key to the shape of the current global higher education system.
\end{abstract}

T. Furukawa $(\bowtie) \cdot$ N. Shirakawa

National Institute of Science and Technology Policy, 16th Floor, Central Government Building No. 7.

East Wing, 3-2-2 Kasumigaseki, Chuyoda-ku, Tokyo 100-0013, Japan

e-mail: furukawa@nistep.go.jp

K. Okuwada

Research Institute of Science and Technology for Society, Japan Science and Technology Agency, K's Gobancho Building, 7, Gobancho, Chuyoda-ku, Tokyo 102-0076, Japan 
Keywords International mobility - Graduate students · Research universities · World university rankings $\cdot$ Push-pull model

\section{Introduction}

Globalization of higher education is characterized by worldwide competition and knowledge transfer across borders (Teichler 2004), and the nature of the current globalization of higher education has attracted significant attention from students, faculty, staff, educators, and policymakers. An increase in the number of international students is a recently observed quantitative effect caused by the globalization of higher education and further promoting it at the same time. International student mobility in higher education has often been discussed from the perspective of the migration of potential highly skilled workers (e.g., Brooks and Waters 2009, 2011; Cantwell 2011), a process that is relevant to brain drain and brain circulation in the context of global workforce issues. Several organizations, such as the Organisation for Economic Co-operation and Development (OECD) and the Institute of International Education (IIE), have gathered statistical data about international student movement (IIE 2011; OECD 2009; 2010). These data enable a macro-analysis of international student mobility among countries (e.g., McMahon 1992). Banks et al. (2007) forecast that global demand for international students in higher education will grow from 2.173 million in 2005 to 3.720 million in 2025. In addition, using a macro-model, they predict the number of international students by country. In macro-studies, economic disparity has been extracted as a significant factor of international student mobility (e.g., McMahon 1992). Macro-models are not fit for detailed analysis of global student flows focusing on specific institutions, disciplines, etc. Several previous studies have attempted to analyze cross-border mobility among higher education institutions (e.g., Li and Bray 2007), but the findings are difficult to generalize because the studies need to take into account the cultural, social, and economic backgrounds of the countries concerned as well as private circumstances of individual students.

The circumstances surrounding international student mobility profoundly affect policymaking decisions related to the higher education system in every or virtually every country, where the acquisition of talented graduate students, especially those who will become skilled scientists and engineers, is a focus of increasingly intense effort for governments as well as educational institutions. In the present paper, we focus on educational backgrounds of scientists and engineers in several fields that are closely related to high technology industry. The purpose of this study is to substantiate the state of international mobility of talented graduate students who will publish scholarly research in their future careers as scientists and engineers, and to present the mechanism of their movement between institutions.

This article is organized as follows. In the next section, we briefly review related studies on international student mobility and indicate the necessity of institutional-level mesoanalysis and comparative study for students in different research domains. Next, we introduce the sources and data collection procedures used for the analysis, which investigates the biographical notes attached to journal articles written by 7,053 unique authors from 1,671 institutions awarding academic degrees. We discuss international mobility for future scientists and engineers at graduate school in terms of three research domains: computer vision, robotics, and electron devices. Furthermore, we examine results showing institutional-level graduate student mobility across national borders and discuss them from the perspectives of university ranking, research domains, and university classification. We conclude with a look at the contribution and limitations of this study. 


\section{Push-pull model analysis of international student mobility}

Studies on international student mobility can be roughly categorized into motivation analyses based on data obtained from questionnaires for international students (e.g., Mazzarol and Soutar 2002; Park 2009) and mathematical flow analyses based on statistical data (McMahon 1992; González et al. 2011). In both types of studies, the push-pull model is useful to describe the bilateral flow of international students from their home country to the host country, because mobility effects can be divided into pull factors in the host country and push factors in the home countries.

Mazzarol and Soutar (2002) showed, based on the studies of prospective undergraduate and postgraduate students in East Asian countries, that the economic and social situation in the home country acts as a push factor and that knowledge and awareness of the host country act as pull factors. In their study, the selection process in international student moves is divided into three stages: (1) choice of foreign or home country, (2) choice of host country, and (3) choice of host institution. They also discuss institutional reputation as a pull factor for international students (Mazzarol and Soutar 2002). For Korean high school students who were considering studying abroad in university, Park (2009) analyzed the driving force and directional factors that can also be considered in a push-pull model. Park's study suggests that academic and cultural-environmental expectations are the main pull factors when students choose a host country. Li and Bray (2007) investigated crossborder students who had moved from mainland China to Hong Kong and Macau, demonstrating that the reputation of an institution is a pull factor in a student choosing a host institution. Chen (2007) subdivided the push-pull model into country and institution selection phases, though that paper's investigation is limited to two host universities in Canada only. Cantwell et al. (2009) argued that student movement from developed countries to Mexico mainly depends on private factors, a finding that is valuable because the population it assesses differs from those of the previous studies that look at student flows from economically developing countries to developed countries. Cantwell et al. (2009) also showed that academic university ranking is a significant factor attracting students to Mexican universities from other Latin American countries. Kondakci (2011) made the push-pull model more sophisticated by introducing the concepts of pre-/postdeparture rationales and public/private rationales, applying this model to international students in Turkey. The results suggest that economic and academic rationales are the major pull factors for students from economically developing countries, while in contrast, private rationales are the pull factors for students from developed countries.

McMahon (1992) introduced mathematical models that describe bilateral international student flows reflecting economic conditions such as GDP per capita, trade levels, expenditure on education, and secondary school enrollment ratio. Consequently, economic disparity can be extracted as the main factor in promoting international student mobility. Chen and Barnett (2000) applied network analysis to international student exchanges, showing that economically developed countries such as the United States and European countries are located in the center of the network of international student attraction. González et al. (2011) proposed a mathematical model describing bilateral student flows within the Erasmus program. The results indicate that an institution's position in the world university rankings acts as a significant pull factor, at least for universities in the top 200.

In terms of push-pull factors on international students, various economic, social, and political environments and private preferences have been considered in previous studies. In a country-level macro-analysis of bilateral flows of international students, economic disparity has been found to be a significant and reasonable factor in promoting student 
mobility (e.g., McMahon 1992). Even though the macro-model can consider various factors related to student mobility, it is difficult to extract in detail factors depending on institutions, disciplines, and so on. Meanwhile, in questionnaire-based micro-analysis of international student mobility using a push-pull model, detailed factors tend to be personal preferences for specific countries (e.g., Mazzarol and Soutar 2002). Hence, meso-analysis of institutional-level student mobility across national borders has been insufficient due to the difficulty in data collection. On the other hand, the various world university rankings have become popular and attracted attention from stakeholders in higher education in many countries, so that recent studies have appeared examining the effect of university ranking on institutional reputation (González et al. 2011; Kahanec and Králiková 2011). Differences in the rankings by discipline were not reflected in these analyses. Relationships between discipline and international mobility of people working in that discipline have also been pointed out (Stephan and Levin 2001, Laudel 2003, 2005).

In the current paper, we highlight the following issues related to international mobility of future scientists and engineers at graduate schools.

- Institutional-level meso-analysis focusing on the mobility of talented graduate students across national borders.

- Comparative study of different research domains within the engineering field and close to industry.

\section{Sources and data}

This article uses an institutional-level meso-analysis to assess international mobility of talented graduate students in different research domains. Since public statistical data are currently insufficient to assess worldwide student mobility between institutions, we collect original data for this analysis.

\section{Biographical notes and author trajectory}

To be able to comprehend international student mobility between institutions of higher education, we investigate the authors' biographical notes that are attached to journal articles. Scholarly articles published by the Institute of Electrical and Electronics Engineers (IEEE), which is the largest professional association for electronics-related disciplines, normally contain brief biographical notes, which include the following example:

The author received the BTech degree in electrical engineering from Indian Institute of Technology, Bombay in 1997 and the MS degree from the University of Illinois, Urbana-Champaign in 1999. Since August of 1999, he has been working as a system engineer at QUALCOMM Inc., where he is working on design and development of the cdma2000 reverse link.

By analyzing these biographical notes, we can obtain the following information about the institutions the author attended, in chronological order:

- Institution awarding the bachelor's degree: Indian Institute of Technology, Bombay

- Institution awarding the master's degree: University of Illinois, Urbana-Champaign

- Institution awarding the doctoral degree: Not available in this case (presumably, no doctoral degree). 
The connections between these institutions enable us to trace the trajectory of the author's background in higher education (Furukawa et al. 2011, 2012), which will typically show us a graduate student moving from the institution awarding the bachelor's degree to the institution awarding the doctoral degree via the institution awarding the master's degree. It should be noted that even though three institutions cannot always be obtained from the biographical notes, in cases where an institution awarding a doctoral degree is not given, the large number of samples makes up for this deficiency. Another limitation is that biographical notes are not always available for scientific journals such as Nature and Science.

The samples used in this investigation do not cover all graduate students, since they are limited to authors who have published a minimum of one journal article, either during or after their graduate career. Therefore, samples are interpreted to represent scientists working as faculty members at universities or engineers working in the R\&D sections of enterprises, as well as applicants for these positions (graduate students who have published a journal paper). Hence, we analyze the international mobility of talented graduate students who published scholarly articles as scientists and engineers, either as graduate students or later on. Mobility is represented by moves between institutions as a student. Mobility among Ph.D. students contributes to network building, which in turn promotes collaboration (Bienkowska and Klofsten 2012); therefore, graduate student mobility can profoundly shape the future careers of the students. Thus, it is worthwhile to analyze the international mobility of talented graduate students.

Data

Several studies have pointed out that international mobility of scientists and engineers varies by discipline. In the United States, the percentage of foreign-born scholars in mathematics and computer science is greater than that in other disciplines (Stephan and Levin 2001). For elite scientists with many publications, there is a stronger tendency to brain drain in the biomedical sciences compared with scientists in the physical sciences (Laudel 2005). In the case of big science, as represented by high-energy physics, several developed countries have few institutions with required facilities like huge accelerators. Therefore, research environment is the most significant pull factor in mobility in big science. In the humanities, international mobility of students is notably affected by cultural background, including the languages spoken in the host country. In theoretical research like that done in mathematics, it is not necessary to consider discipline-specific factors affecting the international mobility of scientists. In the present paper, we mainly focus on engineering fields, which policymakers and taxpayers look for economic benefit. Hence, this paper selects the following three research domains in the engineering fields.

(a) Computer vision research represented by image understanding such as face recognition contributes to the creation of IT startup companies, leading to innovation.

(b) Robotics is a next-generation industrial field that ranges from manufacturing to medical application, which has potential to create new markets and jobs.

(c) Electron device research represented by semiconductor is foundational in electronics industries that generate a huge economic impact.

It is useful to discuss the relationship between the international mobility of talented graduate students and the skilled workforce, because these research domains are closely related to industry. 
Table 1 Selected research domains, journals, and datasets

\begin{tabular}{|c|c|c|c|c|c|}
\hline $\begin{array}{l}\text { Research } \\
\text { domain }\end{array}$ & Journal title & $\begin{array}{l}\text { Period of } \\
\text { publication }\end{array}$ & $\begin{array}{l}\text { Number } \\
\text { of papers }\end{array}$ & $\begin{array}{l}\text { Number } \\
\text { of authors }\end{array}$ & $\begin{array}{l}\text { Number of } \\
\text { unique authors }\end{array}$ \\
\hline $\begin{array}{l}\text { Computer } \\
\text { vision }\end{array}$ & $\begin{array}{l}\text { IEEE Transactions on Pattern } \\
\text { Analysis and Machine Intelligence }\end{array}$ & 1997-2009 & 1,294 & 3,437 & 2,361 \\
\hline \multirow[t]{3}{*}{ Robotics } & IEEE Transactions on Robotics & 2004-2009 & 493 & 1,487 & 1,157 \\
\hline & Robotics and Autonomous Systems & 2004-2009 & 540 & 1,672 & 1,382 \\
\hline & Subtotal $^{\mathrm{a}}$ & & 1,033 & 3,159 & 2,441 \\
\hline $\begin{array}{l}\text { Electron } \\
\text { devices }\end{array}$ & $\begin{array}{l}\text { IEEE Transactions on Electron } \\
\text { Devices }\end{array}$ & $2008-2009$ & 584 & 2,919 & 2,251 \\
\hline
\end{tabular}

\footnotetext{
a Subtotal does not equal the sum of journals in robotics, because some authors published different articles in both journals
}

Table 1 summarizes the source data: journal title, period of publication, and number of articles, including both the number of authors and the number of unique authors. Criteria for journal selection are as follows:

1. The journals have bibliographical notes attached to regular papers that can be used to analyze author trajectory.

2. The journals are published monthly, so that we can obtain enough articles for analysis.

3. The journals have high impact factors, ${ }^{1}$ reflecting their influence in their respective research domains.

We retrospectively investigated papers published from December 2009 until we accumulated a number of authors close to 3,000. The periods investigated are not the same across the three research domains, since the number of journals and papers published within a month differs across them. However, this difference can be neglected, because the age distribution of authors is adequately dispersed.

The "number of authors" includes duplication, reflecting scientists who have published several articles, but the "number of unique authors" does not. We investigated 7,053 unique authors in total, more than 2,200 in each research domain, and extracted information on the institutions at which these authors had earned bachelor's, master's, and doctoral degrees from the biographical notes. The institution names showed variation owing to the different languages used and to the use of abbreviations. ${ }^{2}$ We therefore checked and unified these variations to maintain consistency and accuracy. In the end, we obtained 1,647 institutions awarding academic degrees, from 93 countries.

Table 2 shows the number of unique authors awarded academic degrees from identified institutions, in which the percentage within parenthesis indicates a percentage of the identified data. Some authors only gave their doctoral degrees and not their bachelor's or master's degrees in the biographical notes, so that we could not obtain institutions awarding bachelor's degree for one-third of unique authors. Some graduate and

\footnotetext{
${ }^{1}$ In 2005, the three IEEE Transactions journals were ranked at the top by impact factor for each research domain. In robotics research, IEEE Transactions on Robotics started in 2004, splitting from a former journal covering scope control theory as well as robotics. Hence, we add another robotics journal, called Robotics and Autonomous Systems, which was ranked fourth in impact factor in 2005, since criteria (1) and (2) were not satisfied for the second-or third-ranked journals.

${ }^{2}$ For example, École Polytechnique Fédérale de Lausanne is often described by the abbreviation EPFL or by the English notation Swiss Federal Institute of Science and Technology, Lausanne.
} 
Table 2 Number and percentage of unique authors who were awarded academic degrees from identified institutions, by research domain

\begin{tabular}{llll}
\hline Research domain & \multicolumn{2}{l}{ Academic degree } & \\
\cline { 2 - 4 } & Bachelor's & Master's & Doctorate \\
\hline Computer vision & $1,343(70 \%)$ & $1,392(59 \%)$ & $1,744(74 \%)$ \\
Robotics & $1,646(67 \%)$ & $1,316(54 \%)$ & $1,565(64 \%)$ \\
Electron devices & $1,478(66 \%)$ & $1,369(61 \%)$ & $1,239(55 \%)$ \\
\hline
\end{tabular}

undergraduate students were also included among the unique authors, so that we could not obtain doctoral or master's degrees for some unique authors.

\section{Characteristics of graduate student mobility}

To obtain an overview of the characteristics of graduate student mobility for each institution, we analyze the number of degrees awarded by each institution out of the available data shown in Table 2. Figure 1 shows a ternary diagram (e.g., Bradley 2007) reflecting the relationship between the total number of degree holders and the proportions (ratios) of each degree in each research domain. The total number of degree holders by institution is the sum of the identified doctoral, master's, and bachelor's degree holders and is the denominator calculating the ratios. Thus, Fig. 1 reflects only data shown in Table 2. Sphere sizes and positions indicate the total number of degree holders and the ratio of doctoral, master's, and bachelor's degree holders. If doctorates account for $100 \%$ of the degrees awarded by a university, that is, if all bachelor's and master's degrees were awarded from other universities, then the university is located at the top of the triangle. If master's or bachelor's degrees account for $100 \%$ of the degree holders from a university, then the university is located at the bottom right or bottom left of the triangle, respectively. If the ratio of the three types of degrees from a university is relatively balanced, the university is located at the center of the triangle. The institutions located at the top and the bottom right of the triangle tend to receive students who graduated from other universities, because their number of undergraduate students is relatively low. In contrast, the institutions located at the bottom left tend to send undergraduate students to other institutions. For institutions that award a large number of degrees over all, the institution's name is shown and the corresponding sphere is colored white to designate it. The numbers within parenthesis indicate the university's position in the discipline of engineering/technology and computer science according to the Academic Ranking of World Universities 2011 (SRC 2011). The detailed calculations used to determine each institution's position in the triangle are included in the appendix.

Major institutions in each research domain

For each research domain, we compare the major universities that award the largest number of degrees. In Fig. 1a, the Massachusetts Institute of Technology (MIT) has awarded the highest number of total degrees in computer vision, followed by Tsinghua University in Beijing, the University of Tokyo, and the Technion-Israel Institute of Technology.

Figure $1 \mathrm{~b}$ indicates the extracted universities in robotics, with the major universities located in North America, Europe, and East Asia. Another major university in robotics is 
Fig. 1 The total number of degree holders and the proportion (ratio) of doctoral, master's, and bachelor's degree holders. Sphere diameter indicates the total number of degree holders. Sphere position reflects the ratio of doctoral, master's, or bachelor's degree holders to the total. The numbers within parentheses indicate the school's position in the discipline of engineering/ technology and computer science in the Academic Ranking of World Universities if this number is higher than 100. (a) Computer vision research domain. Named institutions each awarded more than 33 degrees in total.

(b) Robotics research domain. Named institutions each awarded more than 33 degrees in total. (c) Electron device research domain. Named institutions each awarded more than 32 degrees in total
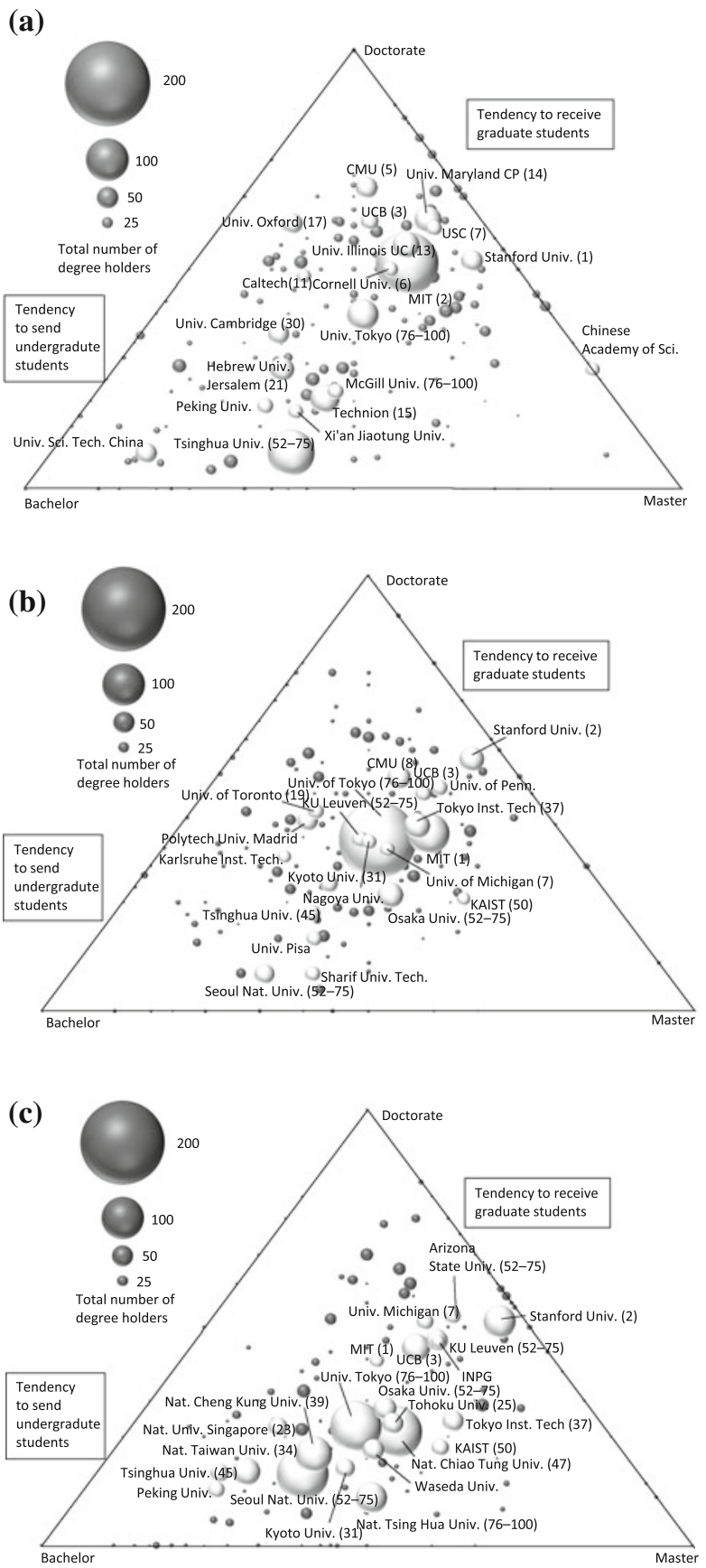

Sharif University of Technology in Tehran. Japanese universities are located at almost the center of the triangle, the point at which doctoral, master's, and bachelor's degree holders are almost in balance. The University of Tokyo awarded the highest number of total degrees, followed by MIT and the Tokyo Institute of Technology. 
Regarding the major universities in electron devices (Fig. 1c), National Chiao Tung University in Taiwan awarded the highest number of total degrees, followed by Seoul National University (SNU) and the University of Tokyo. Other notable institutions include Katholieke Universiteit Leuven (KU Leuven) in Belgium and Institut National Polytechnique de Grenoble (INPG) in France, as well as several universities in the United States.

Characteristics of graduate student mobility in each research domain

Sphere distributions differ in Fig. 1a-c, which suggests that graduate student mobility is dependent on research domain. In Fig. 1a, we see that the spheres in computer vision are widely distributed along the slanted left edge, connecting the top and the bottom left of the triangle. The two clusters divide the triangle into top-right and bottom-left regions. In Fig. 1a, more spheres are located in the top region of the triangle as compared to Fig. 1b, c. This result suggests that universities with computer vision programs tend to enroll many students who have graduated from other universities and to award many doctoral degrees, compared to those with programs in robotics and electron devices. The Chinese Academy of Sciences (CAS) has an independent graduate school that offers no undergraduate program; therefore, the sphere indicating CAS is located on the right edge, connecting the top and the bottom right of the triangle.

In Fig. 1b, the spheres showing institutions in robotics are mostly concentrated in the center of the triangle. The institutions awarding a high number of degrees in electron devices, in Fig. 1c, have their spheres distributed along the edge connecting the top and the bottom left of the triangle. Again, two clusters divide the institutions into top-right and bottom regions. Moreover, the large spheres corresponding to universities in Taiwan, South Korea, Japan, and China are concentrated in the bottom region. This suggests that these institutions send many undergraduate students to other institutions and that engineers coming from them who do not earn a Ph.D. contribute articles to scholarly journals on electron devices as well.

\section{Graduate student mobility patterns}

Because we do not consider international mobility of graduate students between institutions in the previous section, in this section we extract pairs of individual universities from Fig. 1 and then analyze the graduate student flows between the bachelor's, master's, and doctoral degree programs offered by these institutions.

\section{Stanford University and Carnegie Mellon University}

Several universities are always located in the top-right area of the triangle in Fig. 1a-c. For example, Stanford University in the United States is representative of institutions that receive many graduate students from other institutions. Fig. 2 illustrates the flow of students who earned a Ph.D. from Stanford. The arrow's thickness indicates the number of students who moved between institutions. In Fig. 2, the institutions are categorized by degree type (i.e., bachelor's, master's, and doctoral). The figure shows that undergraduate students from universities in various countries enter the master's degree programs in these engineering fields at Stanford University. Moreover, master's degree holders from Stanford University account for a large portion of the Ph.D. holders from Stanford. This result 


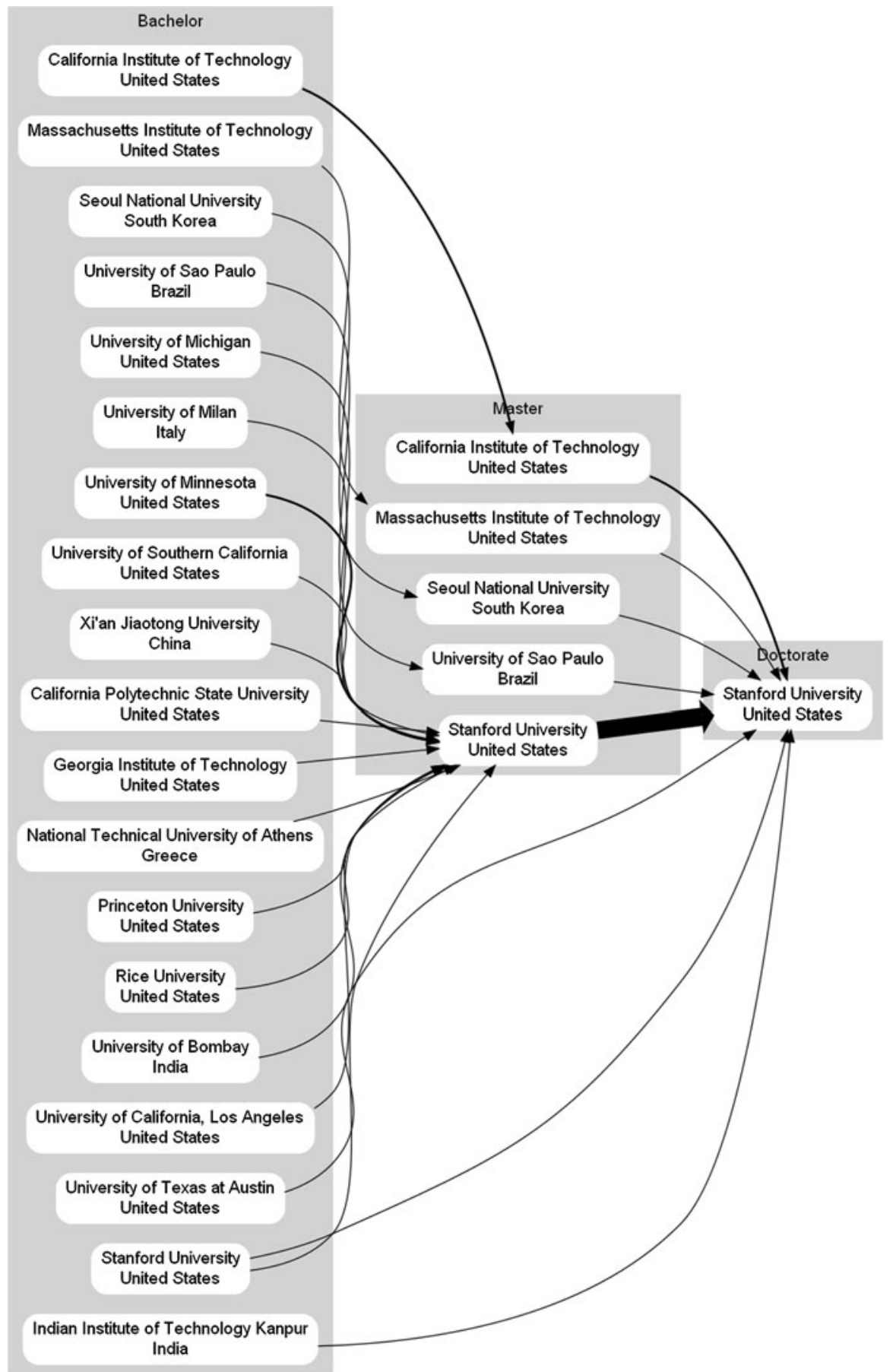

Fig. 2 Trajectories of 26 authors who earned a Ph.D. from Stanford University, as obtained from journal articles on computer vision. The arrow thickness indicates the number of students who moved between institutions 
suggests that the master's course at Stanford University serves undergraduate students from all over the world and retains many of them for doctoral studies.

Carnegie Mellon University (CMU), also in the United States, is another typical example of a university that receives many graduate students from other institutions. Figure 3 illustrates the flow of students in computer vision who earned a Ph.D. from CMU, as derived from the biographical notes of authors who published scholarly articles on computer vision. Ph.D. holders from CMU come from various universities, including Stanford. However, the percentages of bachelor's and master's degree holders from CMU are very low compared with those from Stanford University. This result suggests that the doctoral program at CMU attracts mostly master's degree holders from various graduate schools other than its own.

\section{Tsinghua University and Seoul National University}

Tsinghua University in China is representative of universities that send undergraduate students to other institutions, as seen at the bottom left of the triangle in Fig. 1a-c. Figure 4 shows the trajectories of authors who earned their bachelor's degree from Tsinghua University in computer vision. Many bachelor's degree holders from Tsinghua University pursued master's degree courses at overseas institutions, though the percentage of students entering graduate school at Tsinghua is also very high. Moreover, we can see that bachelor's degree holders from Tsinghua University earned a Ph.D. mainly from research universities in the United States. Figure 4 therefore suggests that alumni from Tsinghua University provide significant input to these research universities in the form of incoming Ph.D. students. Seoul National University (SNU) is also a typical university sending undergraduates to other institutions, especially in the United States. Figure 5 shows the trajectories of authors who have published articles on electron devices and who earned bachelor's degrees from SNU. Many of these authors have entered various master's and doctoral degree courses from institutions in the United States. Even though a high percentage of bachelor's degree holders from SNU also enroll in graduate school at that same university, many others earned their Ph.D. from universities in the United States.

\section{Massachusetts Institute of Technology and University of Tokyo}

Massachusetts Institute of Technology (MIT) is located near the center of the three triangles in Fig. 1a-c, which indicates that inbound and outbound mobility of graduate students are roughly in balance. Figure 6 shows the trajectories of authors of robotics articles who earned master's degrees from MIT. These students came to MIT after obtaining their bachelor's degree from any of a variety of institutions throughout the world, although the percentage of bachelor's degree holders from MIT is higher than that of those coming from other institutions. Moreover, most of these master's degree holders also earned their Ph.D. from MIT. The University of Tokyo is located almost at the center of the triangles in Fig. 1a-c, which signifies that the inbound and outbound mobility of graduate students are in balance. Figure 7 shows the trajectories of authors of robotics articles who earned their master's degrees from the University of Tokyo; more than $90 \%$ of them also earned both bachelor's and doctoral degrees from Tokyo. Both MIT and the University of Tokyo can thus be considered balanced institutions in terms of the ratios of doctoral, master's, and bachelor's degree holders. However, the undergraduate institutions that send students to MIT are much more diverse than are those for the University of Tokyo. 


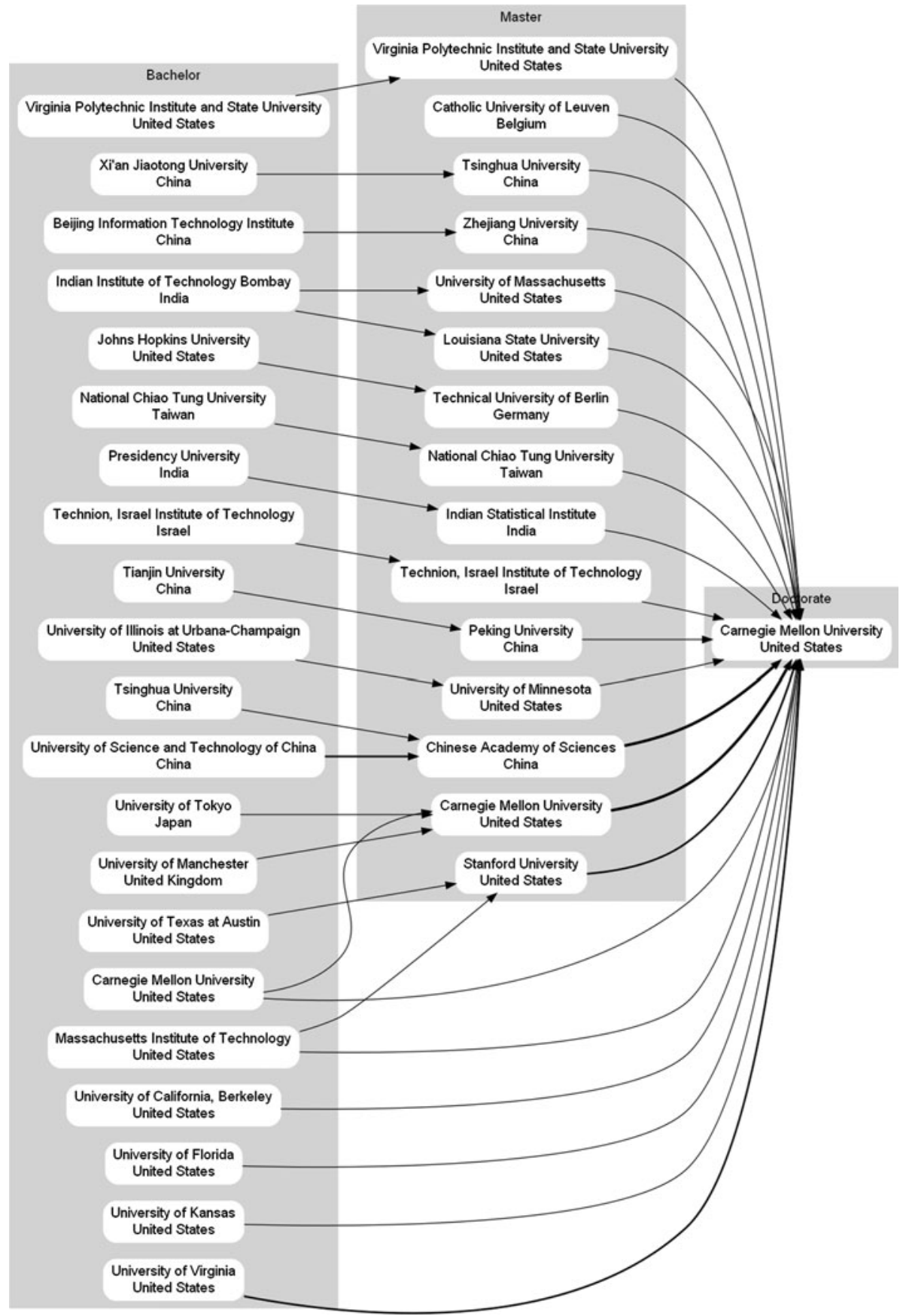

Fig. 3 Trajectories of 35 authors who earned a Ph.D. from Carnegie Mellon University, as obtained from journal articles on computer vision. The arrow thickness indicates the number of students who moved between institutions 


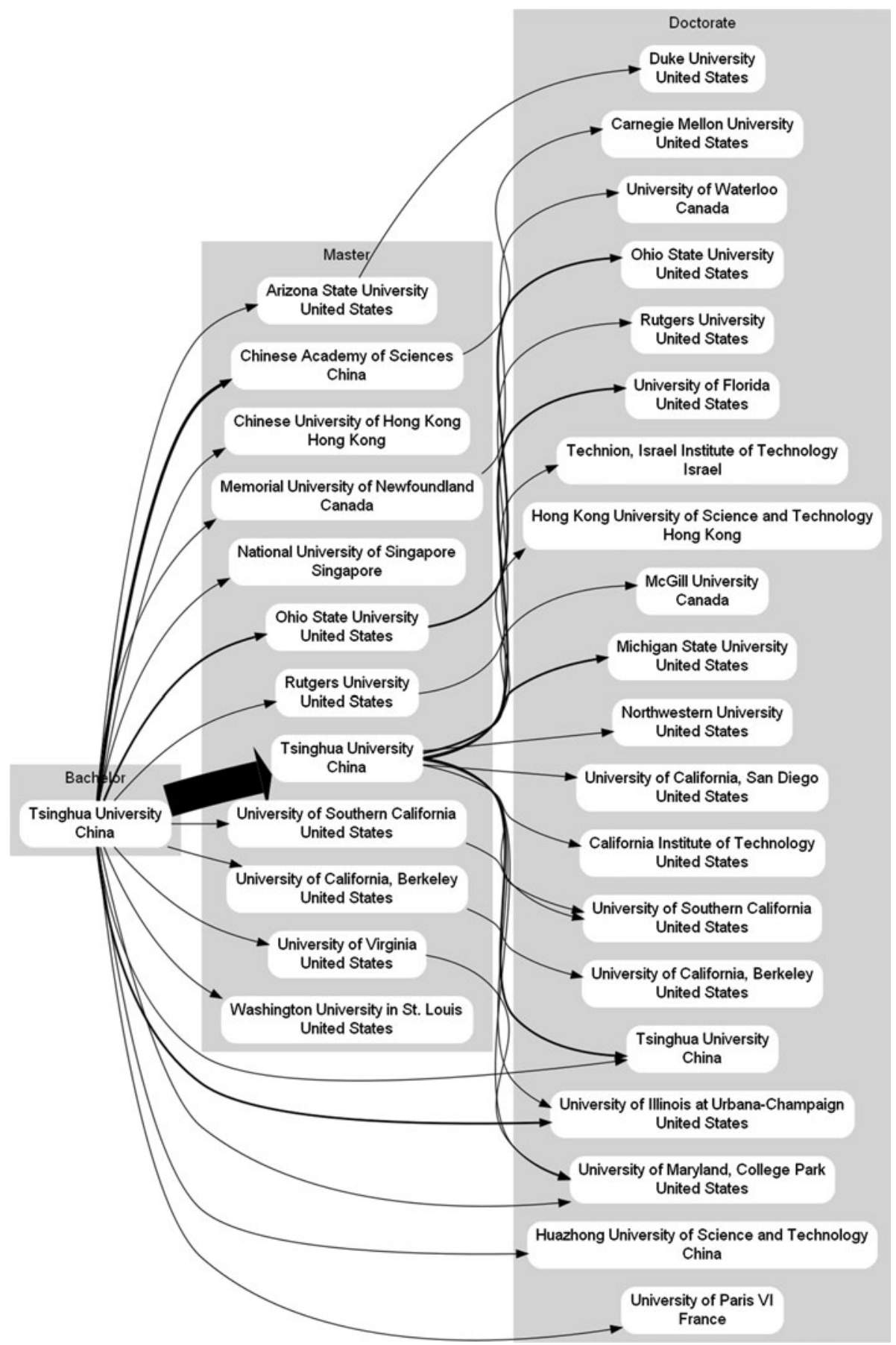

Fig. 4 Trajectories of 61 authors who earned a bachelor's degree from Tsinghua University, as obtained from journal articles on robotics. The arrow thickness indicates the number of students who moved between institutions 


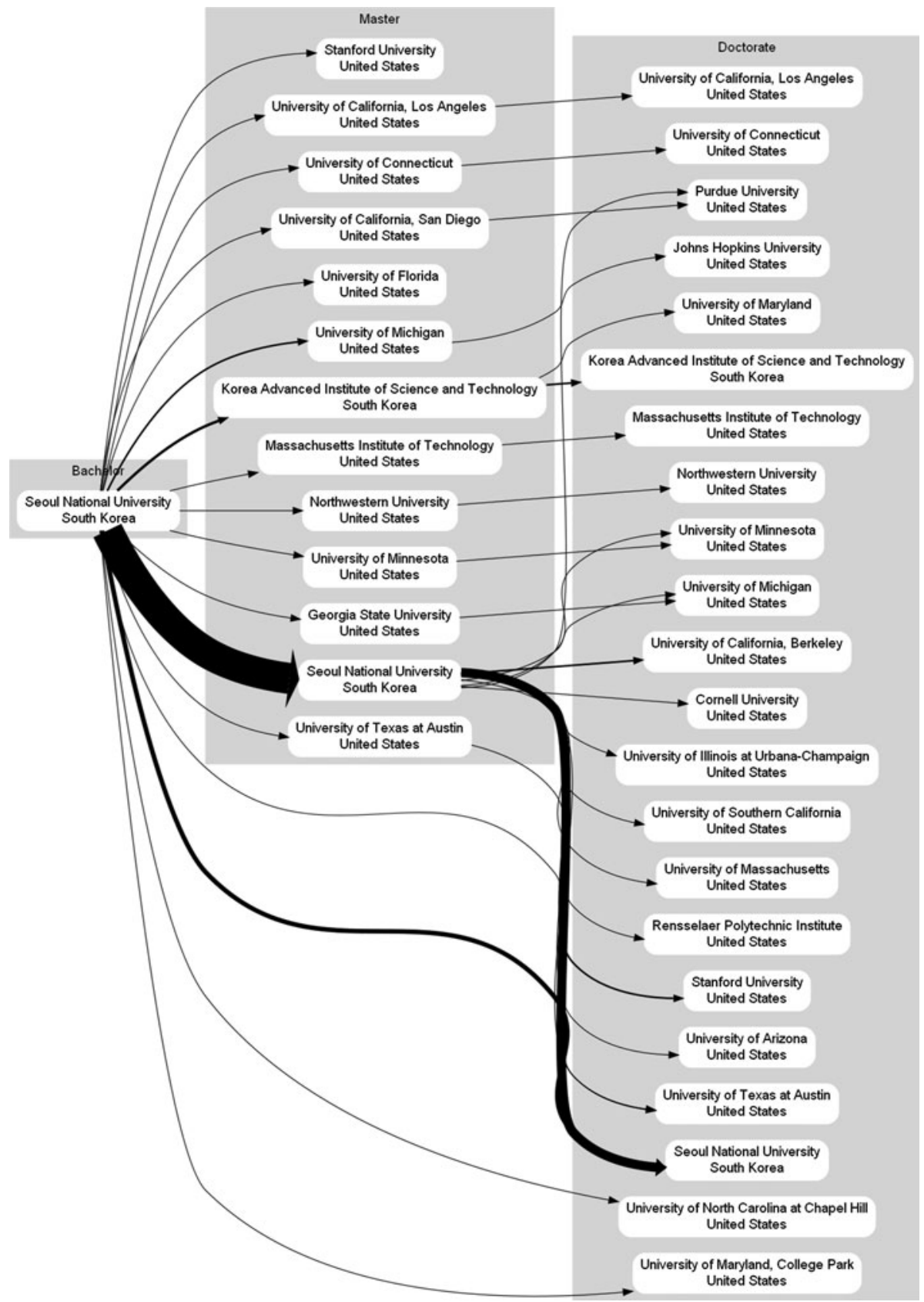

Fig. 5 Trajectories of 63 authors who earned a bachelor's degree from Seoul National University, as obtained from journal articles on electron devices. The arrow thickness indicates the number of students who moved between institutions 


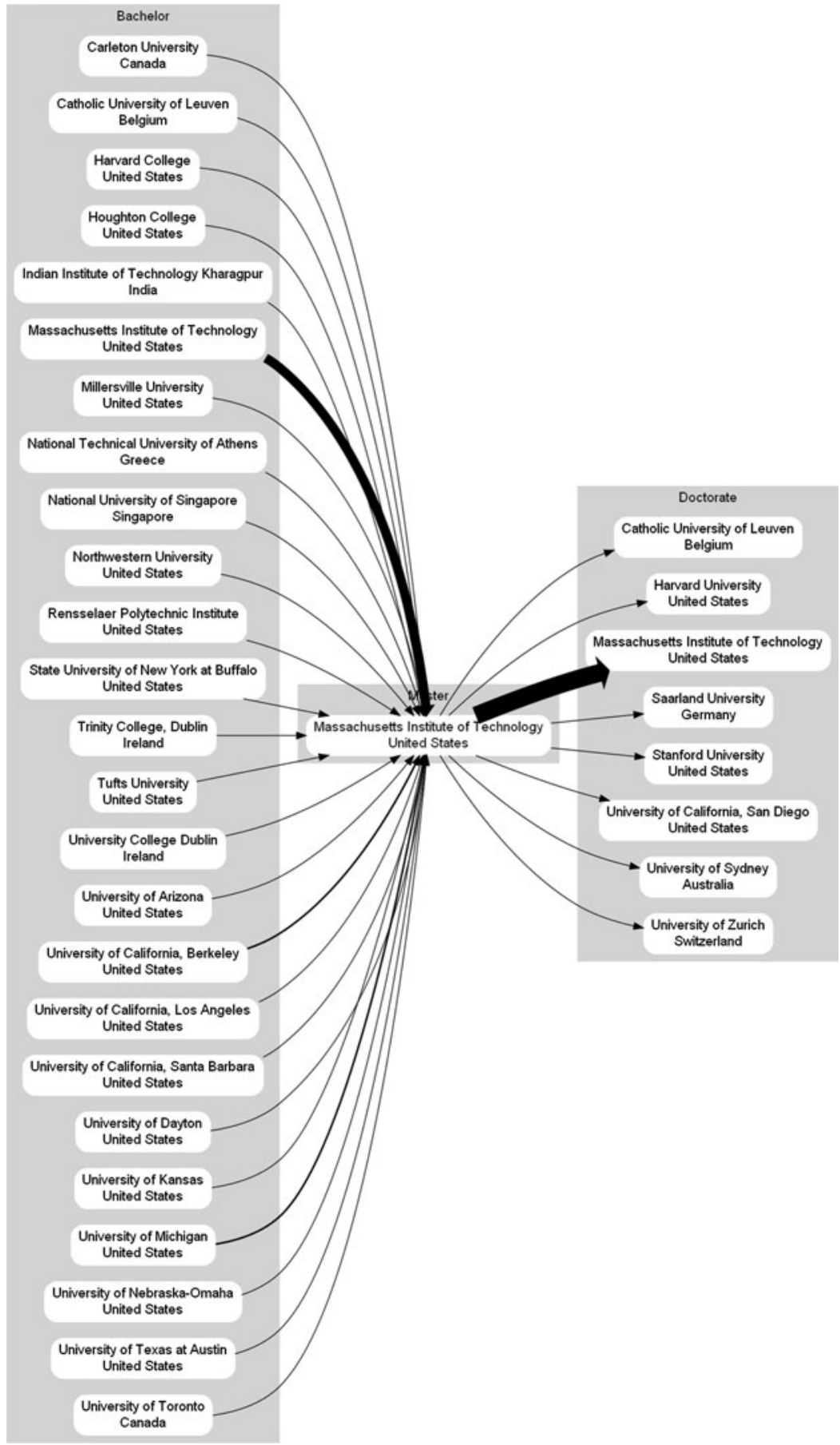

Fig. 6 Trajectories of 38 authors who earned a master's degree from the Massachusetts Institute of Technology, as obtained from journal articles on robotics. The arrow thickness indicates the number of students who moved between institutions 


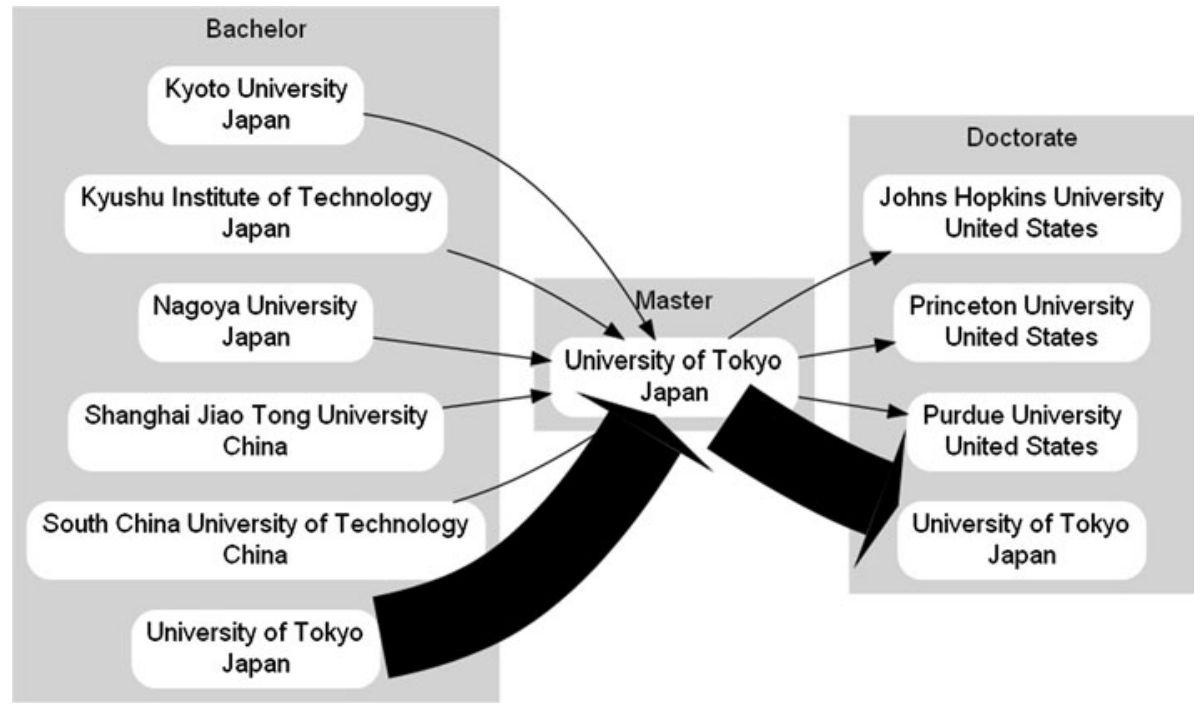

Fig. 7 Trajectories of 58 authors who earned a master's degree from the University of Tokyo, as obtained from journal articles on robotics. The arrow thickness indicates the number of students who moved between institutions

\section{Discussion}

In this section, we discuss the mechanism which shapes the international graduate student mobility demonstrated in the previous section in terms of world university rankings, research domains, and university classification.

Graduate student mobility and world university rankings

Currently, the major world university rankings, such as the Times Higher Education World University Rankings (THE 2012) and the Academic Ranking of World Universities (SRC 2011), produced by ShanghaiRanking Consultancy and also known as the Shanghai ranking, attract considerable attention from stakeholders in higher education. In the world university rankings, especially the Shanghai ranking (Liu and Cheng 2005), academic research accounts for a large portion of the institutional evaluation. Because the present study examines scientists and engineers, individuals in research-intensive fields, it is appropriate in the mobility analysis to discuss the relationship between the researchfocused university rankings and graduate student mobility.

If an institution's position in the discipline of engineering/technology and computer science in the Academic Ranking of World Universities is higher than 100, the position is indicated by the number within parentheses in Fig. 1. We found first that the top ten universities in the United States, as represented by Stanford University and MIT, tend to enroll undergraduate students from foreign universities as well as other universities in the United States, especially in the field of computer vision, as shown in Fig. 1a. A similar tendency can be observed in robotics, as shown in Fig. 1b. This tendency supports the view that the world university ranking is a significant pull factor in student mobility in higher education (González et al. 2011). The results of this investigation suggest the possibility 
that global flows of graduate students from lower- to higher-ranked universities enhance the definite US-oriented stratification of higher education institutions among talented graduates in the three research domains mentioned. Second, we found that two universities in Israel tend to send undergraduate students to other institutions even though they hold a high position in the university rankings, as shown in Fig. 1a. This suggests that economic, social, and political pull factors also exist, a finding that cannot be neglected when we consider micro-mobility.

\section{Graduate student mobility and research domains}

As González et al. (2011) point out the world university ranking acts as a pull factor in institutional selection by international students, Fig. 1a, b shows that universities with a high position in the discipline of engineering/technology and computer science in Shanghai rankings tend to attract undergraduate students globally in these disciplines. However, the results for electron devices suggest a possible alternative force outside of university rankings. Mathews and Cho (2000) substantiated the rapid growth of the semiconductor industry in East Asian countries, in particular South Korea and Taiwan, in the 1990s. Saxenian (2006) discusses the fact that US-educated entrepreneurs who returned home to Taiwan after graduation made the major contribution to the speedy development of the semiconductor industry in Taiwan. These studies suggest that electronics industries like semiconductors have a large economic impact and have created considerable domestic employment for highly skilled workers in East Asian countries, which may be a factor affecting the international mobility choices of talented graduate students. Nevertheless, job-related issues such as job opportunities in the home country (Cantwell et al. 2009) and the value of a degree in the employment market (Li and Bray 2007) are not the primary factor in the international mobility of students, but merely one important factor. For highly skilled prospective workers in East Asian countries, job opportunities in electronics may be a pull factor in the choice of a domestic graduate school. Furthermore, employment for highly skilled software engineers in the United States, as represented by Silicon Valley, may also be considered a pull factor for international graduate students in computer vision. However, further discussion on this topic is required that considers in more depth the relationship between flows of talented graduate students and domestic industries.

\section{Graduate student mobility and university classification}

From the perspective of policymaking for and administration of higher education, nurturing talented students, especially in graduate schools, and providing highly skilled workers to the labor market are key issues. In previous sections, we have suggested the possibility that the world university rankings and the chance of domestic employment for scientists and engineers act as pull factors for graduate students in the investigated research domains. We have identified some representative institutions of several sorts in terms of their role in the international mobility of talented graduate students, though we do not provide comprehensive findings on institutions. Thus, in this section, we discuss the relationship between university classification and graduate student mobility, which provides useful information for the design of a better public higher education system.

Regarding the similarities and dissimilarities between systems used for the classification and ranking of universities, McCormick (2008) discussed the application of a classification technique called the Carnegie classification (e.g., Shulman 2001) to university ranking. Although the Carnegie classification is sophisticated, the categories that tend to be used to 
classify universities in the United States are not suitable from the aspect of international student mobility. Regarding institutional classification for globalizing higher education, therefore, Marginson (2006) presented five types of institutions:

1. World market of elite universities,

2. Exporting national research universities,

3. Teaching-focused export institutions,

4. Nationally bound research universities and

5. Lesser-status national/local institutions.

Our results roughly coincide with these categories and also indicate additional issues concerning graduate student mobility. For example, Stanford University can be categorized as an elite university, while CMU, with its specialty in computer science, is also categorized as an elite university from the perspective of receiving international students in this field. Tsinghua University is classified as both an exporting national research university and a teaching-focused export institution. SNU is both an intermediate-level exporting national research university and a teaching-focused export institution, because it accepts many of its undergraduate students into its own Ph.D. programs as well as sending them to research universities in the United States. The University of Tokyo is categorized as a nationally bound research university. Because we analyzed the authors of scholarly articles who work at universities as well as public and private research institutions, the number of institutions categorized into lesser-status national/local institutions is not enough to discuss.

The results of this classification suggest that there are complementary relationships between top-ranked research universities such as MIT, Stanford University, CMU, and so on, and exporting national research universities such as Tsinghua University and SNU. Consequently, we see that exporting national research universities underpin top research universities by providing excellent undergraduate students to the top institutions. On the other hand, even among top-ranked elite universities, patterns of graduate student mobility are different between Stanford University and CMU. Both schools are representative of universities that receive many undergraduate students from other universities; however, graduate student mobility patterns are different between them. The source institutions of $\mathrm{Ph} . \mathrm{D}$. holders who receive their degrees from CMU are more diverse in comparison with those from Stanford. Further investigation into this difference is needed.

In terms of policy implications, we see that institutions in category 2 , exporting national research universities, and 3, teaching-focused export institutions, seem to aim at 1 , the world market of elite universities. A high position in university rankings and high mobility of talented graduate students among these institutions would help accentuate this trend. On the other hand, there is another trend in which category 4 institutions, nationally bound research universities, also aim at 1 , the world market of elite universities, by improving their position in the world university rankings. However, the low international mobility of students from nationally bound research universities may be an obstacle to shifting their access to the world market of elite universities, an issue that is prominent in Japan and is also observed in Taiwan, which has a large domestic labor market for scientists and engineers.

It is important to remember that these findings are limited to engineering research fields that are closely related to industry in East Asian counties; in these fields, this paper suggests a significant connection between student demands from higher education and the needs of the domestic labor market. 


\section{Conclusion}

In this article, we analyzed the mobility of talented graduate students between institutions worldwide awarding bachelor's, master's, and doctoral degrees, based on data obtained from the biographical notes of authors who have published journal articles in the fields of computer vision, robotics, and electron devices, focusing on their time as graduate students. Our analysis of the global flows of 7,053 students between 1,671 institutions demonstrates a clear overall tendency and leads to the emergence of representative institutions in several categories for these three research domains. As González et al. (2011) point out, the world university rankings act as a pull factor in institutional selection by international students, with worldclass research universities that hold a high position in the university ranking attracting undergraduate students from other institutions around the world in the computer vision and robotics research domains. The world university rankings are a significant pull factor in the global mobility of talented graduate students who become scientists and engineers in computer vision and robotics, which may in turn promote a US-dominated stratification between institutions of higher education. Meanwhile, we suggest the possibility that employment for highly skilled workers like engineers in $R \& D$ in the domestic electronics industry is an alternative pull factor for graduate students in East Asian countries. Without institutionallevel mobility analysis by research domain, this tendency could not have been identified. Further, we showed that five categories of institutions in the realm of globalized higher education (Marginson 2006) are basically characteristic from the perspective of graduate student mobility. Furthermore, we suggest that complementary relationships between topranked research universities and exporting national research universities are concealed behind the university rankings, which means that top-tier research universities are underpinned by exporting national research universities, which provide excellent undergraduate students. Consequently, the exporting national research universities are a necessary part of the supply chain of talented graduate students needed in order for the high-ranking research universities to maintain a dominant position in the globalizing higher education market.

China and India have exported professionals as well as students to Western countries since the 1970s, and brain drain has been widely considered a serious problem in those two countries. In China, the situation has been changing since 1990, following the improvement of economic and academic conditions under policies implemented by initiatives including the 985 and 211 projects (Altbach 2009), which foster the inbound mobility of academic staff. Statistics on the international mobility of academic staff are now being gathered in European countries, but there have been difficulties in classifying types of academic staff, disciplines, and so on (Teichler et al. 2011). The analysis presented in this article does not cover mobility of scientists and engineers after they have been awarded their terminal degrees, and this is a subject that should be investigated further in the future. Moreover, new trends such as the emergence of transnational education have already been developing (Bhandari and Blumenthal 2011). This phenomenon may allow institutions to increase their global mobility, which may in turn reduce the need for students to move about internationally. For higher education systems, which are globalizing and evolving, a sophisticated methodology will be required to better understand this complex situation.

Acknowledgments This work was partially supported by a Grant-in-Aid for Scientific Research (C) from JSPS (No. 22500875).

Open Access This article is distributed under the terms of the Creative Commons Attribution License which permits any use, distribution, and reproduction in any medium, provided the original author(s) and the source are credited. 
Fig. 8 Visualization method for four components. a Diameter reflecting a scalar value. b Subdivided triangles reflecting the ratio of three components
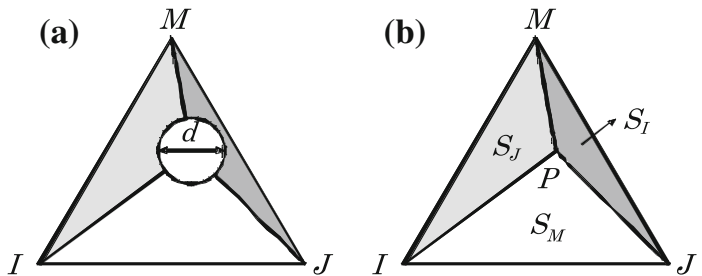

\section{Appendix: Visualization of four components}

The source data comprise the total number of degree holders and the proportions (ratios) of doctoral, master's, and bachelor's degree holders for each institution. We reflect the total number of degree holders to the diameter of a sphere $d$, as shown in Fig. 8a. Moreover, we reflect the ratio among the doctoral, master's, and bachelor's degree holders by the areas of sub-triangles $S_{I}, S_{J}$, and $S_{M}$ in Fig. $8 \mathrm{~b}$.

We denote the coordinates of points $I, J, M$, and $P$ by $\left(x_{I}, y_{I}\right),\left(x_{J}, y_{J}\right),\left(x_{M}, y_{M}\right)$, and $(x$, $y$ ), respectively. Triangular areas $S_{I}, S_{J}$, and $S_{M}$ are expressed as follows:

$$
S_{1}=\frac{1}{2}\left|\begin{array}{ccc}
1 & 1 & 1 \\
x & x_{J} & x_{M} \\
y & y_{J} & y_{M}
\end{array}\right|, \quad S_{J}=\frac{1}{2}\left|\begin{array}{ccc}
1 & 1 & 1 \\
x & x_{M} & x_{I} \\
y & y_{M} & y_{I}
\end{array}\right|, \quad S_{M}=\frac{1}{2}\left|\begin{array}{ccc}
1 & 1 & 1 \\
x & x_{I} & x_{J} \\
y & y_{I} & y_{J}
\end{array}\right|,
$$

where II means a determinant of a square matrix. We assume that $S_{I}, S_{J}$, and $S_{M}$ satisfy the following condition.

$$
S_{I}+S_{J}+S_{M}=1, \quad\left(0 \leq S_{I} \leq 1, \quad 0 \leq S_{J} \leq 1, \quad 0 \leq S_{M} \leq 1\right) .
$$

If we provide the constants $S_{I}$ and $S_{J}$, the coordinates of point $P(x, y)$ can be given by solving the simultaneous equations expressed as follows.

$$
\left\{\begin{array}{l}
S_{I}=\frac{1}{2}\left[\left(x_{J}-y_{M}\right) x+\left(x_{M}-y_{J}\right) y+\left|\begin{array}{ll}
x_{J} & x_{M} \\
y_{J} & y_{M}
\end{array}\right|\right] \\
S_{J}=\frac{1}{2}\left[\left(x_{M}-y_{I}\right) x+\left(x_{I}-y_{M}\right) y+\left|\begin{array}{ll}
x_{M} & x_{I} \\
y_{M} & y_{I}
\end{array}\right|\right]
\end{array} .\right.
$$

\section{References}

Altbach, P. G. (2009). One-third of the globe: The future of higher education in China and India. Prospects, 39(1), 11-31.

Banks, M., Olsen, A., \& Pearce, D. (2007). Global student mobility: An Australian perspective five years on. Sydney: IDP Education Pty Ltd.

Bhandari, R., \& Blumenthal, P. (2011). Global student mobility and the twenty-first century Silk Road: National trends and new directions. In R. Bhandari \& P. Blumenthal (Eds.), International students and global mobility in higher education (pp. 1-23). New York: Palgrave Macmillan.

Bienkowska, D., \& Klofsten, M. (2012). Creating entrepreneurial networks: Academic entrepreneurship, mobility and collaboration during PhD education. Higher Education, 64(2), 207-222.

Bradley, C. J. (2007). The algebra of geometry: Cartesian, areal and projective co-ordinates. Bath: Highperception.

Brooks, R., \& Waters, J. (2009). International higher education and the mobility of UK students. Journal of Research in International Education, 8(2), 191-209. 
Brooks, R., \& Waters, J. (2011). Student mobilities, migration and the internationalization of higher education. London: Palgrave Macmillan.

Cantwell, B. (2011). Transnational mobility and international academic employment: Gatekeeping in an academic competition arena. Minerva, 49(4), 425-445.

Cantwell, B., Luca, S. G., \& Lee, J. J. (2009). Exploring the orientations of international students in Mexico: Differences by region of origin. Higher Education, 57(3), 335-354.

Chen, L. H. (2007). Choosing Canadian graduates from afar: East Asian students' perspectives. Higher Education, 54(5), 759-780.

Chen, T., \& Barnett, G. A. (2000). Research on international student flows from a macro perspective: A network analysis of 1985, 1989 and 1995. Higher Education, 39(4), 435-453.

Furukawa, T., Shirakawa, N., \& Okuwada, K. (2011). Quantitative analysis of collaborative and mobility networks. Scientometrics, 87(3), 451-466.

Furukawa, T., Shirakawa, N., Okuwada, K., \& Sasaki, K. (2012). International mobility of researchers in robotics, computer vision and electron devices: A quantitative and comparative analysis. Scientometrics, 91(1), 185-202.

González, R. C., Mesanza, R. B., \& Mariel, P. (2011). The determinants of international student mobility flows: An empirical study on the Erasmus program. Higher Education, 62(4), 413-430.

Institute of International Education (IIE). (2011). Open doors 2011: Report on international educational exchange. New York: Institute of International Education.

Kahanec, M., \& Králiková, R. (2011). Pulls of international student mobility, IZA discussion paper no. 6233.

Kondakci, Y. (2011). Student mobility reviewed: Attraction and satisfaction of international students in Turkey. Higher Education, 62(5), 573-592.

Laudel, G. (2003). Studying the brain drain: Can bibliometric methods help? Scientometrics, 57(2), $215-237$.

Laudel, G. (2005). Migration currents among the scientific elite. Minerva, 43(4), 377-395.

Li, M., \& Bray, M. (2007). Cross-border flows of students for higher education: Push-pull factors and motivations of mainland Chinese students in Hong Kong and Macau. Higher Education, 53(6), 791-818.

Liu, N. C., \& Cheng, Y. (2005). The academic ranking of world universities. Higher Education in Europe, 30(2), 127-136.

Marginson, S. (2006). Dynamics of national and global competition in higher education. Higher Education, $52(1), 1-39$.

Mathews, J. A., \& Cho, D. S. (2000). Tiger technology: The creation of a semiconductor industry in East Asia. Cambridge: Cambridge University Press.

Mazzarol, T., \& Soutar, G. N. (2002). "Push-pull" factors influencing international student destination choice. International Journal of Education Management, 16(2), 82-90.

McCormick, A. C. (2008). The complex interplay between classification and ranking of colleges and universities: Should the Berlin principles apply equally to classification? Higher Education in Europe, 33(2-3), 209-218.

McMahon, M. E. (1992). Higher Education in a world market: A historical look at the global context of international study. Higher Education, 24(4), 46-482.

Organization for Economic Co-operation and Development (OECD). (2009). Higher education to 2030. Vol. 2: Globalisation. Paris: OECD.

Organization for Economic Co-operation and Development (OECD). (2010). Education at a glance 2010: OECD indicators. Paris: OECD.

Park, E. L. (2009). Analysis of Korean students' international mobility by 2-D model: Driving force factor and directional factor. Higher Education, 57(6), 741-755.

Saxenian, A. L. (2006). The new argonauts: Regional advantage in a global economy. Cambridge: Harvard University Press.

ShanghaiRanking Consultancy (SRC). (2011). Academic ranking of world universities 2011. http:// www.arwu.com/.

Shulman, E. S. (2001). The Carnegie classification of institutions of higher education. Menlo Park: Carnegie Publication.

Stephan, P. E., \& Levin, S. G. (2001). Exceptional contribution to US science by the foreign-born and foreign-educated. Population Research and Policy Review, 20(1-2), 59-79.

Teichler, U. (2004). The changing debate on internationalisation of higher education. Higher Education, $48(1), 526$.

Teichler, U., Ferencz, I., \& Wächter, B. (Eds.). (2011). Mapping mobility in European higher education. Vol. 1: Overview and trends. Brussels: European Commission.

Times Higher Education (THE). (2012). World university rankings 2011-2012.http://www.times highereducation.co.uk/world-university-rankings/. 